\title{
INTEGRATION OF LEAN SIX SIGMA FRAMEWORK IN TESTING LABORATORIES QUALITY MANAGEMENT SYSTEM WITH SPECIFIC REFERENCE TO ISO 17025
}

\author{
Santosh Elapanda \\ Research scholar, GITAM Institute of Management \\ GITAM (Deemed to be University), Visakhapatnam, India. \\ U.V. Adinarayana Rao \\ Associate Professor, GITAM Institute of Management, \\ GITAM (Deemed to be University), Visakhapatnam, India.

\section{K.S. Anjaneya Choudary} \\ Retired DGM (Projects), Visakhapatnam Steel Plant \\ Research scholar, GITAM Institute of Management, \\ GITAM (Deemed to be University), Visakhapatnam, India.
}

\begin{abstract}
Lean Six sigma (LSS) is the most widely used improvement strategy in almost all sectors. Initially it was started using in manufacturing and gained popularity across the sectors in short time. As most of the existing Lean Six sigma frameworks / strategies are specific to Manufacturing, Financial \& IT sectors. This article presents Lean Six sigma specific tools and techniques relevant to the testing laboratory and the accreditation requirements as per the ISO 17025 standard. The study outlines the Lean Six sigma framework designed for integration in to the testing laboratory quality management system.
\end{abstract}

Keyword: Lean Six sigma (LSS), Testing laboratories, Quality management system, ISO 17025, DMAIC.

Cite this Article: Santosh Elapanda, U.V. Adinarayana Rao and K.S. Anjaneya Choudary, Integration of Lean Six Sigma Framework in Testing Laboratories Quality Management System with Specific Reference to ISO 17025, Journal of Management, 6(3), 2019, pp. 1-13.

http://www.iaeme.com/jom/issues.asp?JType=JOM\&VType=6\&IType=3 


\section{INTRODUCTION}

Testing laboratories play an important role in the global economic development valued at around 200 billion euros (2017). This sector remains resilient due to long term contracts and global government agreements supplemented by regulations. The laboratories imprinted in all walks of public life from healthcare testing to consumer products testing. Literally, the testing laboratories works for all parts of supply chain. Increasing level of regulation resulted in transformation from a voluntary based test arrangement to mandatory based testing services. The landscape of testing industry is shaping in to new portfolios of data protection and digital technology testing.

Although testing is a promising sector in terms of economic value and global positioning, it also poses challenges in strict compliance with the regulatory requirements parallelly meeting customer demands. One of the regulatory requirements for testing laboratory is laboratory quality management system accreditation. The accreditation is done by the government agencies to keep a tab on the testing laboratories based on their scope of testing. Different compliance requirements need to be complied based on the type of laboratory i.e., ISO 17025 for testing and calibration laboratories \& ISO 15189 for medical laboratories.

The market is very competitive due to many players. In this competitive market, the customer expectations are soared in terms of less turnaround time, low pricing and accurate reports. To meet the customer expectations along with compliance to regulatory accreditation requirements, it is imperative for laboratories to start implementing quality improvement strategies for effective results. Out of the available quality improvement approaches like TQM, six sigma, Lean, Balanced scorecard etc, it seems the popular combined approach of Lean Six sigma is suitable for laboratory environment.

Lean Six sigma (LSS) is a powerful and successful strategy for business improvements. The unique combination of highly successful two business improvement strategies Lean and Six sigma is blended to enable the companies to gain the advantage of the both strategies. For any company to be successful in implementing Lean Six sigma, the below critical success factors are very important.

- Leadership commitment

- Focused resources

- Common tools and instruction language

- Disciplined project approach

- Bottom line business measures

Lean Six sigma is a structured approach for business transformation, which involves the rigorous drive of the key principles in to the organizations strategy and should become the part of the philosophy.

The Key principles of Lean Six sigma are:

- Customer focus

- Identify and understand the process gaps

- Improve and manage the process flow

- Elimination of non-value addition activities / steps

- Reduction of process variation

- Engage and equip the employees

- Standardize the process areas 
Almost all the market sectors evidenced the successful benefits after implementation of Lean Six sigma. For example, Bosch had implemented LSS by partnering with BMGI global consulting firm in India and transformed it operations to business excellence. Similarly, most of the MNC's had already implemented and some has just started LSS journey. But there is a huge gap in using of LSS in MSME sector in India due to costly training programs and inadequate publicity. Few years back, industry associations like Confederation of Indian Industries (CII) and Indian statistical institute (ISI) has started programs for all segments of market and advertising for publicity.

It is not an easy task to deploy the Lean Six sigma (LSS) in to any organization as there will be always a resistance for change. For successful deployment of LSS, the following deployment model is an effective one.

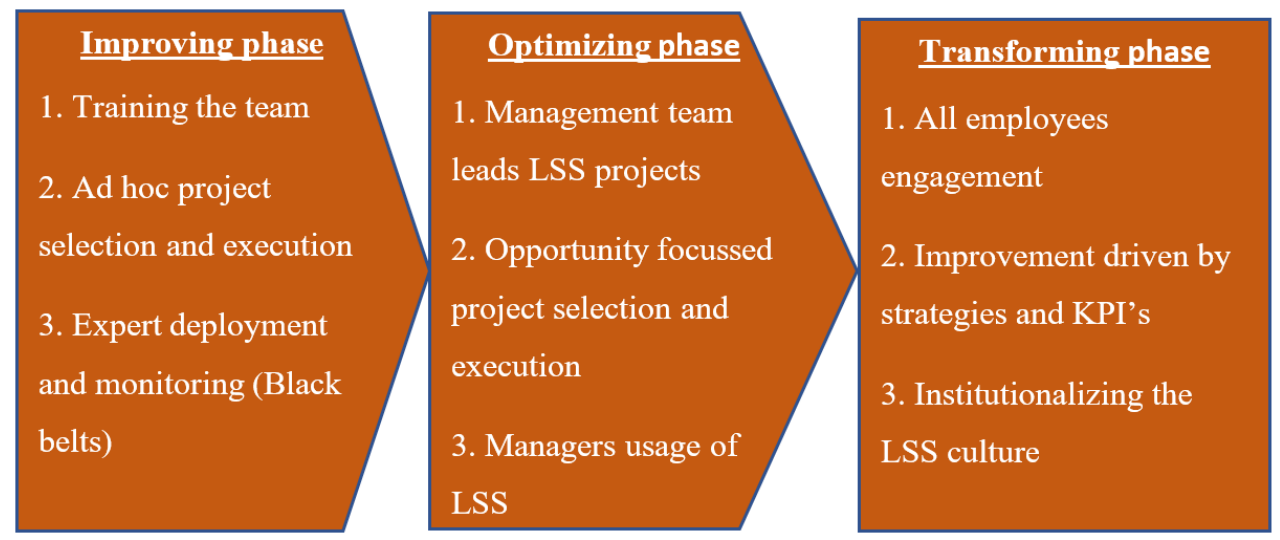

Exhibit 1 Lean and Six sigma deployment

\section{LITERATURE REVIEW}

(Ross, Phillip J, 2008) Products have characteristics that describe their performance relative to customer requirements or expectations. The quality of a product is measured in terms of these characteristics. (Lee et al, 2010) Six Sigma is a well-structured methodology that focuses on reducing variation, measuring defects and improving the quality of products, processes and services. Lean Production is an approach that focuses on reducing the cycle time and eliminating waste in processes. Combining the principles of Six Sigma and Lean can achieve synergistic results that neither system can achieve alone.

(Heuvel et al, 2006) Lean six sigma (LSS) is an integration of Six sigma and Lean manufacturing, both quality improvement programs originating from industry. Lean and Six sigma are highly complementary. Six sigma provides an integrated improvement approach that increases quality by reducing variation, defects and costs. Lean adds tools that increase process throughput by eliminating waste. (Snee, 2010) LSS is a business strategy and methodology that increases process performance resulting in enhanced customer satisfaction and improved bottom line results.

(Atmaca and Girenes, 2011) LSS emerges with the combination of Henry Ford's Lean Manufacturing processes in the early 1960s and the Six Sigma generated by Motorola is the last evolution step in the manufacturing history. Both applications provide to achieve operational effectiveness. This means to apply changes, adding value, to process right at the first time and to act quickly and efficiently. (Salah et al, 2010) In 1986, the George Group in the USA were first to integrate LSS in the manufacturing sector. (Albliwi et al, 2015) But the technique got popularized after 2003. 
(Silva et al, 2012) Six Sigma and Lean, acting together can become even more effective, as their strong points are able to cover the other's gaps or deficiencies. This union may create a synergy, which exercises a great influence over the general performance of the business processes.

(De Koning, H., Does, R.J. and Bisgaard, S., 2008) Lean Thinking and Six Sigma are considered as separate approaches available to process innovation, with complementary strengths. When combined as LSS, this approach provides a unified framework for systematically developing innovations"

(Cloete and Bester, 2012) LSS represents a form of scientific method type, which is empirical, inductive and deductive, and system, which relies on data, and is fact-based. (Mousa, 2013) LSS provides an over-arching improvement philosophy that incorporates powerful datadriven tools to solve problems and create rapid transformational improvement at lower cost.

(Monica Verma, Kiran Dahiya, Veena Singh Ghalaut and Vasudha Dhupper, 2018) Quality Management System includes strict compliance at all phases as error can occur at any step. Sigma metrics is an important self-assessment tool to guide quality control strategy design. It helps to improve the process quality by removing defects. The Six sigma model has the extra step of control, which is important in modern quality management.

(Delgado, C., Ferreira, M. and Branco, M.C., 2010) The benefits derived from LSS implementation, such as lowering the operational costs, improving processes and product quality, increased efficiency, which leads to the increase of productivity, the agility and versatility obtained by the organization, vastly outweigh the costs. At an international level, there are cultural differences pertaining mainly to internal resistance and openness to change.

(V. Raja Sreedharan and R Raju, 2016) LSS research is mainly focused on the manufacturing sector, but LSS has also spread to other type of industries. However, the adoption of LSS in small and medium enterprises is not widespread because of the implementation cost, uncertainty and lack of a clear roadmap for deployment. Papers from different countries like the USA, the UK, India, Malaysia, The Netherlands, etc. show that LSS research is conducted across the globe. The USA and UK are the major publishers in Western countries followed by India and Malaysia in Asia. Authors from developing countries like India have published articles on practical problems in a continuous span of time, showing that the LSS culture is widely spread in India.

After extensive literature review by authors specifically on the Lean Six sigma implementation case studies. Table 1 exhibits the literature review on academic case studies focusing on Lean Six sigma in a wide range of industries. The analysis finds that most of the research papers are published in manufacturing, financial and healthcare sectors. A few are published specifically in clinical laboratories (ISO 15189). It is imperative that there is a good potential for research in laboratories management systems of testing \& calibration laboratories (ISO 17025)

Table 1 List of articles reviewed

\begin{tabular}{|c|c|c|c|}
\hline S. No & Author & Article title & Industry \\
\hline 1 & Lee, K.L., Wei, C.C, 2010 & $\begin{array}{c}\text { Reducing mold changing time by } \\
\text { implementing Lean Six Sigma }\end{array}$ & Manufacturing \\
\hline 2 & $\begin{array}{c}\text { Koning, H., Verver, J.P., } \\
\text { Heuvel, J., Bisgaard, S. and } \\
\text { Does, R.J., 2006 }\end{array}$ & Lean Six Sigma in healthcare & Healthcare \\
\hline 3 & Snee, R.D., 2010 & Lean Six Sigma-getting better all the time & - \\
\hline 4 & Atmaca and Girenes, 2011 & Lean Six Sigma methodology and application & Manufacturing \\
\hline
\end{tabular}


Integration of Lean Six Sigma Framework in Testing Laboratories Quality Management System with Specific Reference to ISO 17025

\begin{tabular}{|c|c|c|c|}
\hline S. No & Author & Article title & Industry \\
\hline 5 & $\begin{array}{l}\text { Salah, S., Rahim, A. and } \\
\quad \text { Carretero, J., } 2010\end{array}$ & $\begin{array}{c}\text { The integration of Six Sigma and Lean } \\
\text { Management }\end{array}$ & Academic \\
\hline 6 & Cloete and Bester, 2012 & $\begin{array}{l}\text { A Lean Six Sigma approach to the } \\
\text { improvement of the selenium analysis method }\end{array}$ & Healthcare \\
\hline 7 & Mousa, 2013 & $\begin{array}{c}\text { Lean, Six Sigma and Lean Six Sigma } \\
\text { overview }\end{array}$ & Academic \\
\hline 8 & $\begin{array}{l}\text { V. Raja Sreedharan and R } \\
\text { Raju, } 2016 \\
\end{array}$ & $\begin{array}{c}\text { A systematic literature review of Lean Six } \\
\text { Sigma in different industries }\end{array}$ & Academic \\
\hline 9 & $\begin{array}{l}\text { Monica Verma, Kiran } \\
\text { Dahiya, Veena Singh } \\
\text { Ghalaut and Vasudha } \\
\text { Dhupper, } 2018 \\
\end{array}$ & $\begin{array}{l}\text { Assessment of quality control system by } \\
\text { sigma metrics and quality goal index ratio: A } \\
\text { roadmap towards preparation for NABL }\end{array}$ & $\begin{array}{l}\text { Healthcare } \\
\text { (Clinical lab) }\end{array}$ \\
\hline 10 & $\begin{array}{c}\text { Silva, A.P.S., Palermo, J.M., } \\
\text { Gibertoni, A., Ferreira, J.A., } \\
\text { Almeida, R.M.A. and } \\
\text { Marroig, L., } 2012 \\
\end{array}$ & $\begin{array}{l}\text { Inventory quality control in clinical } \\
\text { engineering: A Lean Six Sigma approach }\end{array}$ & Healthcare \\
\hline 11 & $\begin{array}{l}\text { Albliwi, S.A., Antony, J. } \\
\text { and Lim, S.A.H., } 2015\end{array}$ & $\begin{array}{c}\text { A systematic review of Lean Six Sigma for } \\
\text { the } \\
\text { manufacturing industry }\end{array}$ & Academic \\
\hline 12 & $\begin{array}{l}\text { Delgado, C., Ferreira, M. } \\
\text { and Branco, M.C., } 2010\end{array}$ & $\begin{array}{l}\text { The implementation of Lean Six Sigma in } \\
\text { financial services organizations }\end{array}$ & Financial services \\
\hline 13 & $\begin{array}{l}\text { De Koning, H., Does, R.J. } \\
\text { and Bisgaard, S., } 2008\end{array}$ & Lean Six Sigma in financial services & Financial services \\
\hline
\end{tabular}

\section{OBJECTIVES}

The objective of this research is to develop a framework by integrating Lean Six sigma in to the Laboratory quality management system (ISO 17025)

\section{METHODOLOGY}

\subsection{Integrated Lean Six sigma framework}

Lean and Six sigma has their own set of tools and techniques towards process improvement, the tools and techniques of Lean and Six sigma are presented in the below exhibit-1. 


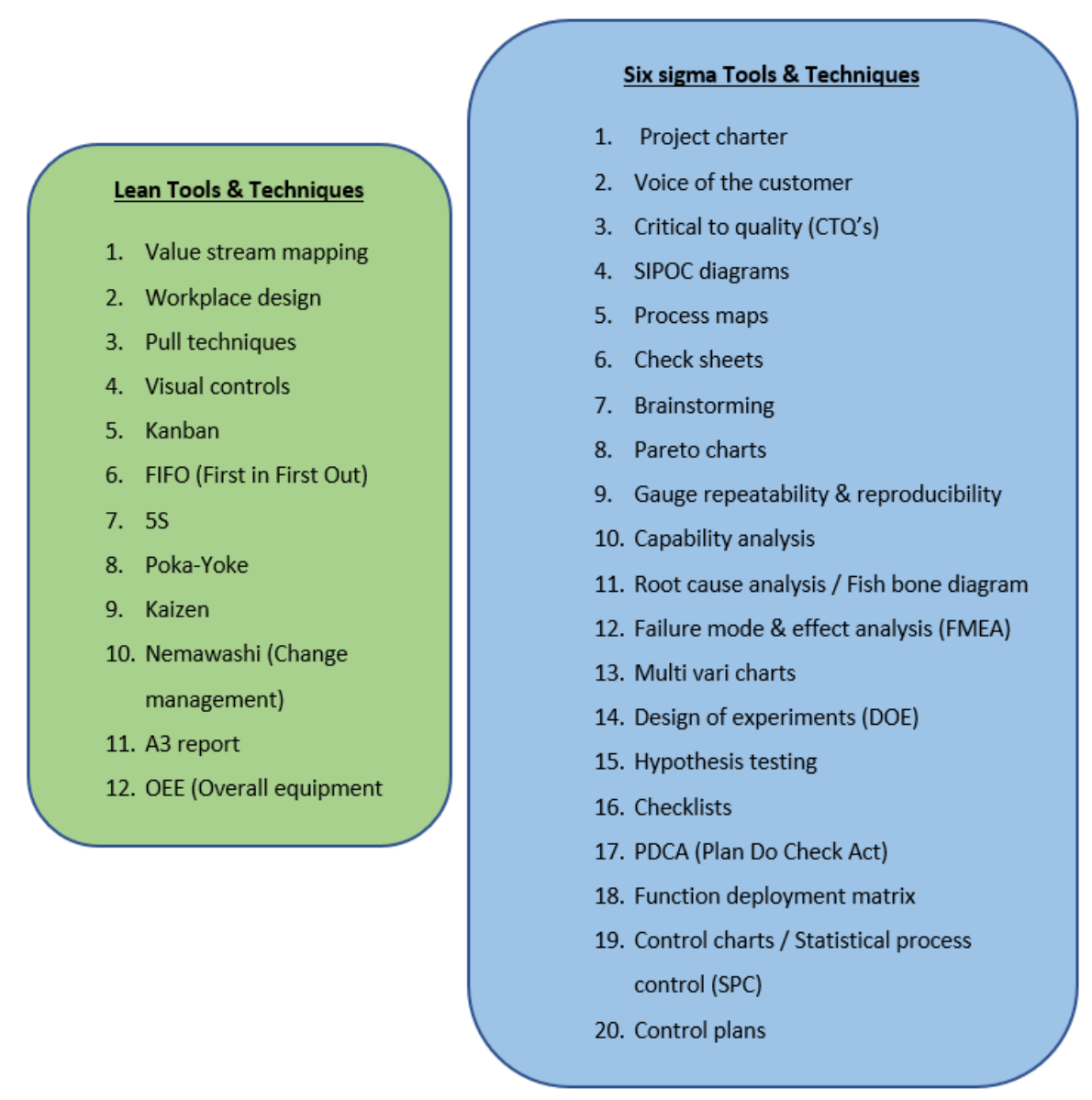

Exhibit 2 Tools and techniques of Lean and Six sigma

There are two widely used approaches DMAIC \& DMADV in Lean Six sigma for process improvement deployment. DMAIC stands for Define, Measure, Analyse, Improve \& Control and DMADV stands for Define, Measure, Analyse, Design \& Verify. The DMAIC methodology (exhibit-2) should be used when a product or process is in existence in a company but is not meeting customer specification or is not performing adequately.

Define: Define phase concentrates on forming the team, defining the project's goals, mapping the process \& identifying customers critical quality requirements.

Measure: Measure phase consists of defining and executing a systematic data collection plan for the key measures (CTQs) for the targeted process.

Analyze: Data collected in the Measure phase are analyzed in the Analyze phase to identify the root causes behind the gap between the current performance and the goals identified in the first phase.

Improve: The Improve phase focuses on identifying expected solutions, suggest set of alternative solutions to enhance performance, and implement some of these solutions according to the available budget and the expected cost for each alternative.

Control: The Control phase concentrates on creating and implementing monitoring and response plans for sustaining improvements, spread out the outcome and the methodology for the whole organization, insure the establishment of a new culture within the organization 
Integration of Lean Six Sigma Framework in Testing Laboratories Quality Management System with Specific Reference to ISO 17025

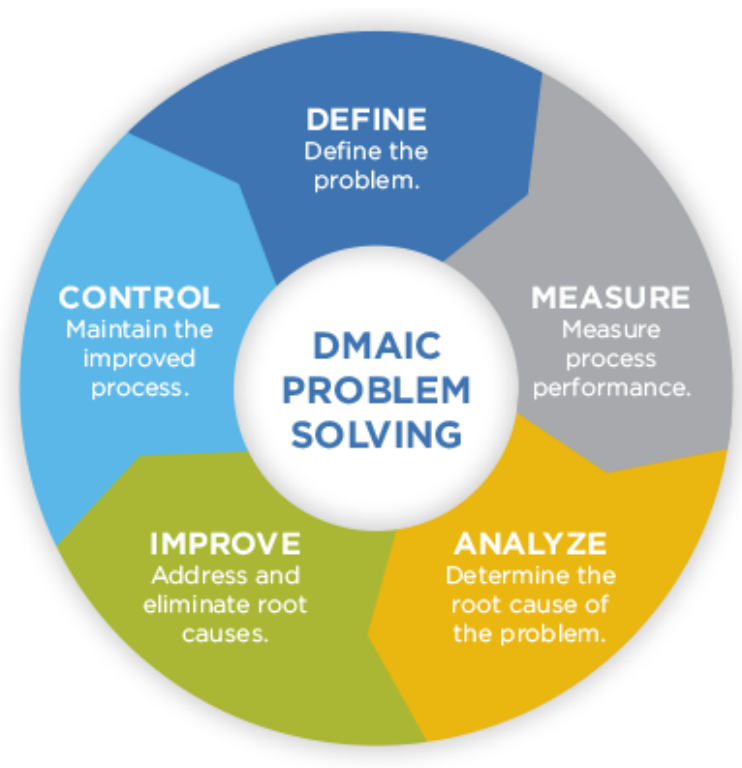

Exhibit 3 DMAIC approach

The DMADV methodology (exhibit-3) should be used when a product or process is not in existence in a company and one needs to be developed.

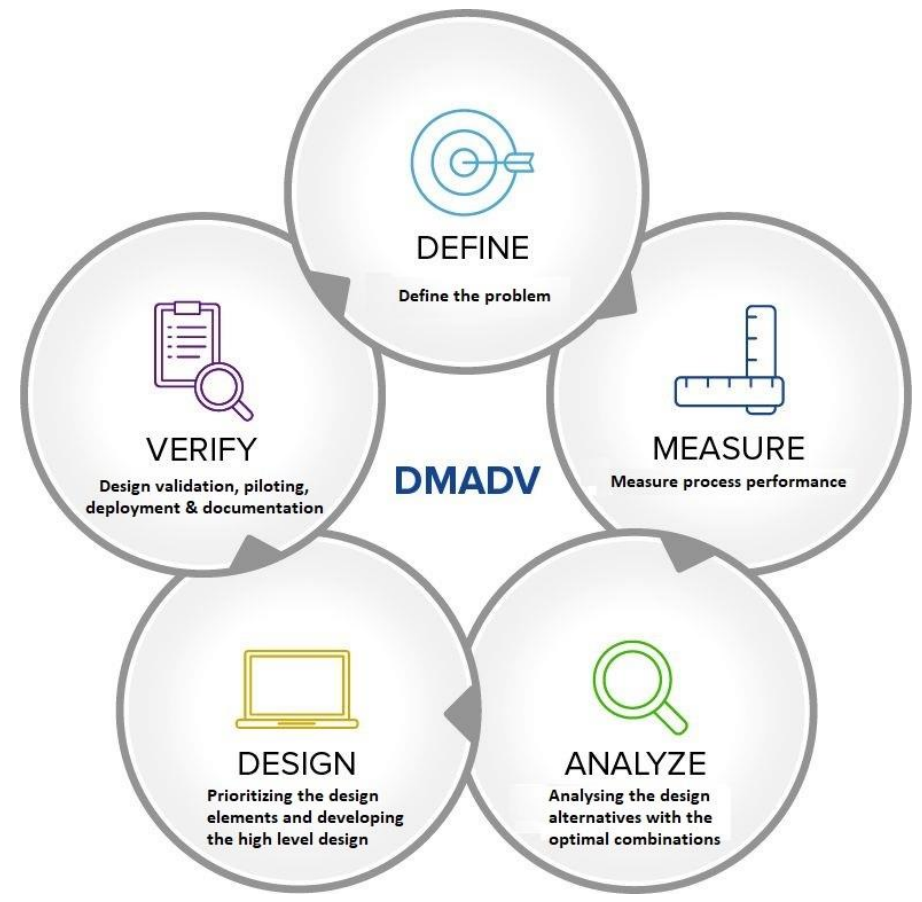

Exhibit 4 DMADV approach

Table 2 Comparison between DMAIC \& DMADV

\begin{tabular}{|c|c|}
\hline DMAIC & DMADV \\
\hline Initiated from a problem & Initiated from an innovation solution / idea \\
\hline Used in existing processes & Used for new processes / products \\
\hline Organization / Customer / Process focused & Customer focused \\
\hline Small team & Big team \\
\hline
\end{tabular}


Santosh Elapanda, U.V. Adinarayana Rao and K.S. Anjaneya Choudary

\begin{tabular}{|c|c|}
\hline DMAIC & DMADV \\
\hline Short to medium time frame projects & Long term projects \\
\hline Incremental improvement & Big leap improvement \\
\hline Many projects available for improvement & Less projects available for improvement \\
\hline Continuous improvement & Re-engineering \\
\hline
\end{tabular}

The DMAIC approach which is shown in exhibit-2 is used in our framework as the process improvement opportunities are explored in the existing laboratory quality management system which is implemented by the laboratories.

\section{ANALYSIS}

The testing laboratories poses the following challenges to use the generalized Lean Six sigma approaches / tools which the other industries use.

- Customers pressure in demanding low turnaround time of test results

- Very little scope for process innovation as the tests are conducted as per National / International standard test methods

- Customers having impression that most of the tests are conducted by latest automated instruments in less time \& more accurately

- Inadequate knowledge on repeatability \& reproducibility of test results by the laboratories as well as customers

In this context, it is required to have a customized Lean Six sigma framework with the right and careful selection of tools and techniques that utmost suit to the laboratories and suitable for integration in to the Laboratory quality management system - ISO 17025.

\subsection{Laboratory Quality Management System (ISO 17025)}

ISO 17025 is an International standard developed by International Organization for Standardization for the testing and calibration laboratories accreditation titled as "General requirements for the competence of testing and calibration laboratories". The latest version of this standard is 2017, which we had taken for consideration. It is also termed as laboratory quality management system by the industry.

ISO 17025:2017 has been developed with the objective of promoting confidence in the operation of laboratories. This standard document contains requirements for laboratories to enable them to demonstrate they operate competently, impartially, consistently and are able to generate valid results. Laboratories that conform to this standard document will also operate generally in accordance with the principles of ISO 9001.

This standard document requires the laboratory to plan and implement actions to address risks and opportunities. Addressing both risks and opportunities establishes a basis for increasing the effectiveness of the management system, achieving improved results and preventing negative effects.

The use of this standard document will facilitate cooperation between laboratories and other bodies, and assist in the exchange of information and experience, and in the harmonization of standards and procedures. The acceptance of results between countries is facilitated if laboratories conform to this standard document.

\subsection{Selection of Lean Six sigma tools and techniques}

The selection of tools and techniques depends on the following factors:

- Type of operations / processes (manufacturing / service industry) 
Integration of Lean Six Sigma Framework in Testing Laboratories Quality Management System with Specific Reference to ISO 17025

- Based on approach used (DMAIC / DMADV)

- Type of data available (Qualitative / Quantitative)

- Based on employee's education / competency levels for understanding and implementation

Based on our laboratory industry case, the below factors are taken in to consideration in selection of lean Six sigma tools and techniques.

- Service industry

- DMAIC approach

- Both qualitative \& quantitative data

- Medium education / competency levels of employees

- Compatibility with the ISO 17025:2017

\subsection{Tools and Techniques selected}

Project charter: Project Charter refers to a statement of objectives in a project. This statement also sets out detailed project goals, roles and responsibilities and identification of stakeholders.

Critical to quality (CTQ) drilldown: CTQ's drilldown are the key measurable characteristics of a product or process whose performance standards or specification limits must be met in order to satisfy the customer. They align improvement or design efforts with customer requirements. CTQs are used to decompose broad customer requirements into more easily quantified elements. CTQ trees are often used as part of Lean Six sigma methodology to help prioritize such requirements.

Process maps: Process mapping is the graphic display of steps, events and operations that constitute a process. It's a pictorial illustration which identifies the steps, inputs and outputs, and other related details of a process by providing a step-by-step picture of the process.

Check sheets: The check sheet is a form (document) used to collect data in real time at the location where the data is generated. The data it captures can be quantitative or qualitative. When the information is quantitative, the check sheet is sometimes called a tally sheet.

Brainstorming: It is a situation where a group of people meet to generate new ideas and solutions around a specific domain of interest by removing inhibitions. People are able to think more freely and they suggest many spontaneous new ideas as possible. All the ideas are noted down and those ideas are not criticized and after brainstorming session the ideas are evaluated

Pareto charts: The Pareto chart is a special type of bar chart or histogram, and is one of the seven quality tools, named after Vilfredo Pareto. It is an analytical tool that graphically demonstrates the Pareto principle or the 80-20 rule. It is used to view causes of a problem in order of severity or impact from largest to smallest.

Fish bone diagram: The Fishbone diagram is an analysis tool that provides a systematic way of looking at effects and the causes that create or contribute to those effects. Because of the function of the Fishbone diagram, it may be referred to as a cause-and-effect diagram. As the design of the diagram looks much like the skeleton of a fish it is called as Fish bone diagram.

Multi-vari chart: Multi-vari charts are a visual way of presenting variability through a series of charts. It is used to measure the quality characteristics as below

- The quality characteristic of interest is measured at two extremes (around its diameter, along its length, or across its surface) and these measurements are plotted as vertical lines connecting the minimum and maximum values over time. 
- The quality characteristic of interest is plotted across three horizontal panels that represent:

- Variability on a single piece

- Piece-to-piece variability

- Time-to-time variability

- The quality characteristic of interest is plotted against upper and lower specifications rather than control limits.

Statistical significance testing: Statistical significance (Hypothesis) testing is the use of statistics to determine the probability that a given hypothesis is true. The usual process of hypothesis testing consists of four steps.

a. Formulate the null hypothesis $H_{0}$ (commonly, that the observations are the result of pure chance) and the alternative hypothesis $H_{a}$ (commonly, that the observations show a real effect combined with a component of chance variation).

b. Identify a test statistic that can be used to assess the truth of the null hypothesis.

c. Compute the P-value, which is the probability that a test statistic at least as significant as the one observed would be obtained assuming that the null hypothesis were true. The smaller the ${ }^{P}$-value, the stronger the evidence against the null hypothesis.

d. Compare the $p$-value to an acceptable significance value $\alpha$ (sometimes called an alpha value). If $p \leq \alpha$, that the observed effect is statistically significant, the null hypothesis is ruled out, and the alternative hypothesis is valid.

Checklists: A checklist is a type of job aid used to reduce failure by compensating for potential limits of human memory and attention. It helps to ensure consistency and completeness in carrying out a task. A basic example is the "to do list". A more advanced checklist would be a schedule, which lays out tasks to be done according to time of day or other factors. A primary task in checklist is documentation of the task and auditing against the documentation.

PDCA (Plan Do Check Act): PDCA is a model that provides a framework for the improvement of a process or system. It can be used to monitor a single issue or guide an entire improvement project or initiative. PDCA was made popular by W. Edwards Deming, who is considered by many to be the father of modern quality control

Control charts: It is used to determine if a manufacturing or business process is in a state of control.

A control chart consists of:

- Points representing a statistic (e.g., a mean, range, proportion) of measurements of a quality characteristic in samples taken from the process at different times (i.e., the data)

- The mean of this statistic using all the samples is calculated (e.g., the mean of the means, mean of the ranges, mean of the proportions)

- A center line is drawn at the value of the mean of the statistic

- The standard deviation (e.g., sqrt(variance) of the mean) of the statistic is also calculated using all the samples

- Upper and lower control limits (sometimes called "natural process limits") that indicate the threshold at which the process output is considered statistically 'unlikely' and are drawn typically at 3 standard deviations from the center line

Control plans: A Control Plan is a method for documenting the functional elements of quality control that are to be implemented in order to assure that quality standards are met for 
a particular product or service. The intent of the control plan is to formalize and document the system of control that will be utilized

Value stream mapping: It is a method for analyzing the current state and designing a future state for the series of events that take a product or service from its beginning through to the customer with reduced wastes as compared to current map. A value stream focuses on areas of a firm that add value to a product or service, whereas a value chain refers to all of the activities within a company.

5S: 5S represents Japanese words that describe the steps of a workplace organization process. English equivalent words are shown in parenthesis

1.Seiri (Sort), 2.Seiton (Set), 3.Seiso (Shine), 4.Seiketsu (Standardize) \& 5. Shitsuke (Sustain)

In simple terms, the five S methodology helps a workplace remove items that are no longer needed (sort), organize the items to optimize efficiency and flow (straighten), clean the area in order to more easily identify problems (shine), implement color coding and labels to stay consistent with other areas (standardize) and develop behaviours that keep the workplace organized over the long term (sustain).

Nemawashi (Change management): It is an informal process of quietly laying the foundation for some proposed change or project, by talking to the people concerned, gathering support and feedback, and so forth. It is considered an important element in any major change, before any formal steps are taken, and successful nemawashi enables changes to be carried out with the consent of all sides.

Visual controls: Visual control methods aim to increase the efficiency and effectiveness of a process by making the steps in that process more visible. The design is deliberate in allowing quick recognition of the information being communicated, in order to increase efficiency and clarity. These signals can be of many forms, from different coloured clothing for different teams, to focusing measures upon the size of the problem and not the size of the activity and many other diverse examples.

\subsection{Framework design}

To fulfil the purpose of this article stated objective - Integration of Lean Six sigma in Testing laboratories quality management system, it is important to understand the following requirements:

a. ISO 17025 standard specific clause requirements for quality improvement \& control of processes: The clauses of 7.7 (Ensuring the validity of test results), 7.9 (Complaints) and 7.10 (Non- conforming work) are relevant to the quality control and improvement. Also, these three clauses are very key for laboratory accreditation activities.

b. One specific clause (7.7.3) says "Data from monitoring activities shall be analysed, used to control and, if applicable, improve the laboratory's activities. If the results of the analysis of data from monitoring activities are found to be outside pre-defined criteria, appropriate action shall be taken to prevent incorrect results from being reported." This specific requirement makes laboratories to use the quality improvement tools needed to achieve the performance and this study proves worth.

c. Testing laboratory process requirements: Most of the testing laboratories will carry out the testing either by instrumental or wet analysis and sometimes combination of both.

d. After careful study of the above requirements and the tools and techniques limitations, the framework presented below in exhibit- 4 is designed for optimal results and ease of implementation. 


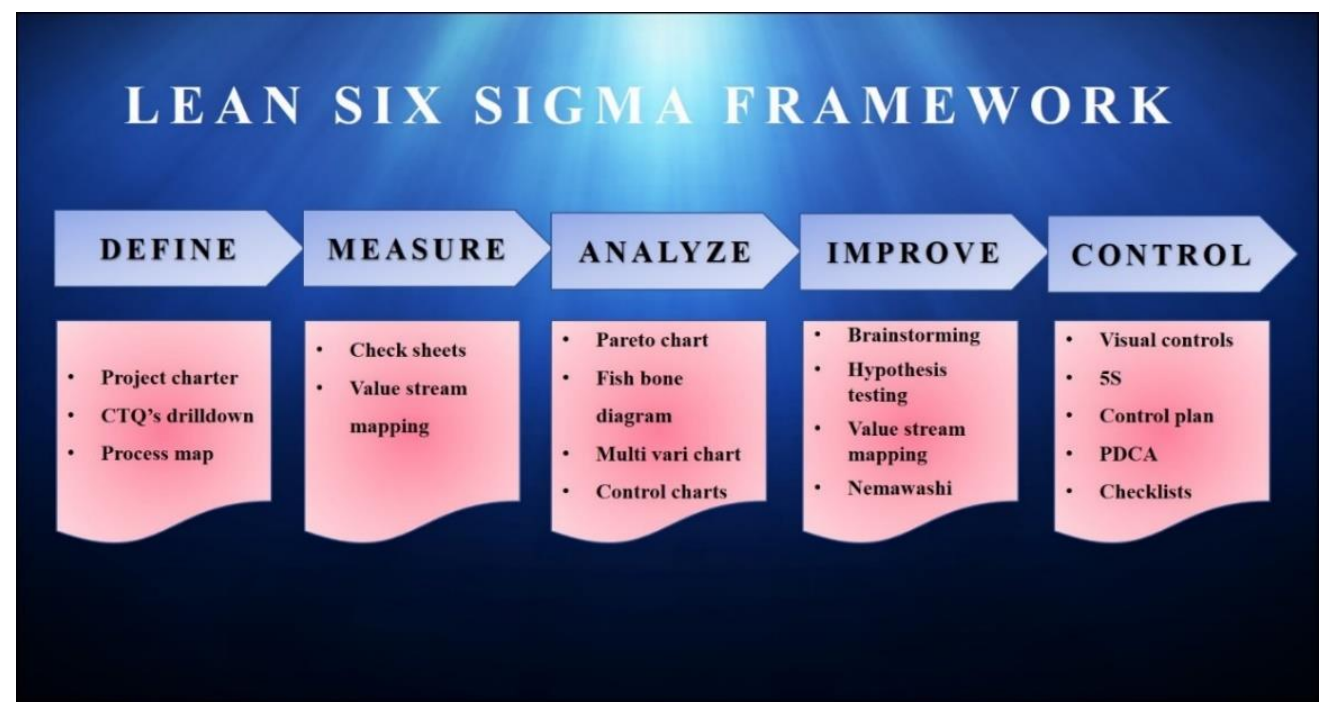

Exhibit 5 Lean Six sigma framework suitable for integration in Testing laboratories quality management system - ISO 17025

\section{CONCLUSIONS}

This paper is an attempt to understand the key factors of implementation of Lean Six sigma in the testing laboratories and the essence of integration of Lean Six sigma in the Laboratory Quality management system (ISO 17025). After analyzing the critical factors and process requirements as per the standard - ISO 17025, the important results are presented below:

i. Identification of appropriate Lean Six sigma tools and techniques relevant to the testing laboratory.

ii. Selection of DMAIC methodology which is suitable for integration \& application.

iii. Understanding the importance of Lean Six sigma in quality control \& improvement of the testing laboratory.

iv. Development of the Lean Six sigma framework along with the methodology and tools $\&$ techniques appropriate to the Laboratory Quality management system (ISO 17025) integration.

\section{REFERENCES}

[1] Lee, K.L., Wei, C.C, 2010. Reducing mold changing time by implementing Lean Six Sigma. Quality and Reliability Engineering International. Volume26, Issue4, P: 387-395.

[2] Koning, H., Verver, J.P., Heuvel, J., Bisgaard, S. and Does, R.J., 2006. Lean Six Sigma in healthcare. J Healthc Qual. 2006 Mar-Apr;28(2):4-11. PMID:16749293

[3] Snee, R.D., 2010. Lean Six Sigma-getting better all the time. International Journal of Lean Six Sigma, Vol. 1 Issue: 1, pp.9-29

[4] Atmaca and Girenes, 2011. Lean Six Sigma methodology and application. Quality \& Quantity, Vol. 4 No. 47, pp. 2107-2127.

[5] Salah, S., Rahim, A. and Carretero, J., 2010. The integration of Six Sigma and Lean management. International Journal of Lean Six Sigma, Vol. 1 No. 3, pp. 249-274.

[6] Cloete and Bester, 2012. A Lean Six Sigma approach to the improvement of the selenium analysis method. Onderstepoort Journal of Veterinary Research, Vol. 79 No. 1.

[7] Mousa, 2013. Lean, Six Sigma and Lean Six Sigma overview. International Journal of Scientific \& Engineering Research, Vol. 4 No. 5, pp. 1137-1153. 
[8] V. Raja Sreedharan and R Raju, 2016. A systematic literature review of Lean Six Sigma in different industries. International Journal of Lean Six Sigma. Vol. 7 No. 4, pp. 430-466.

[9] Monica Verma, Kiran Dahiya, Veena Singh Ghalaut and Vasudha Dhupper, 2018. Assessment of quality control system by sigma metrics and quality goal index ratio: A roadmap towards preparation for NABL. World journal of methodology. Vol 8, Issue 3, ISSN 2222-0682.

[10] Silva, A.P.S., Palermo, J.M., Gibertoni, A., Ferreira, J.A., Almeida, R.M.A. and Marroig, L., 2012. Inventory quality control in clinical engineering: A Lean Six Sigma approach. Pan

[11] American Health Care Exchanges (PAHCE), March, IEEE, pp. 35-39.

[12] Albliwi, S.A., Antony, J. and Lim, S.A.H., 2015. A systematic review of Lean Six Sigma for the manufacturing industry. Business Process Management Journal, Vol. 21 No. 3, pp. 665-691.

[13] Delgado, C., Ferreira, M. and Branco, M.C., 2010. The implementation of Lean Six Sigma in

[14] financial services organizations. Journal of Manufacturing Technology Management, Vol. 21 No. 4, pp. 512-523.

[15] De Koning, H., Does, R.J. and Bisgaard, S., 2008. Lean Six Sigma in financial services. International Journal of Six Sigma and Competitive Advantage, Vol. 4 No. 1, pp. 1-17.

[16] Neha Gupta, 2013. An Application of DMAIC Methodology for Increasing the Yarn Quality in Textile Industry. IOSR Journal of Mechanical and Civil Engineering (IOSRJMCE) e-ISSN: 2278-1684 Volume 6, Issue 1, PP 50-65

[17] Ilie G. and. Ciocoiu C.N. 2010. Application of fishbone diagram to determine the risk of an event with multiple causes. Management research and practice Vol. 2 Issue 1, e-ISSN:20672462, $p: 1-20$.

[18] Jiju Antony, Ronald Snee, Roger Hoerl, (2017) "Lean Six Sigma: yesterday, today and tomorrow". International Journal of Quality \& Reliability Management, Vol. 34 Issue: 7, pp.1073-1093, https://doi.org/10.1108/IJQRM-03-2016-0035.

[19] Abdulrakeeb A. Ghaleb, Mahmoud A. El-Sharief, Mohamed. G. El-Sebaie, 2014. Study of Tools, Techniques and Factors used in Lean Six Sigma. International Journal of Scientific \& Engineering Research, Volume 5, Issue 12, ISSN 2229-5518, p: 1652-1658.

[20] J. Hill, A. J. Thomas, R. K. Mason-Jones \& S. El-Kateb (2018) The implementation of a Lean Six Sigma framework to enhance operational performance in an MRO facility. Production \& Manufacturing Research, 6:1, 26-48, DOI: 10.1080/21693277.2017.1417179. 